\title{
The role of the Office for Outer Space Affairs in support of international coordination on space weather
}

\author{
Simonetta Di Pippo, Sharafat Gadimova, Markus Woltran, Martin Staško \\ Office for Outer Space Affairs, United Nations, Vienna, Austria \\ E mail (sharafat.gadimova@un.org).
}

Accepted: 27 June 2018

\begin{abstract}
Space weather monitoring, prediction and research have become essential pillars of the global response to advance space weather science. A major thrust of the International Heliophysical Year 2007 and the International Space Weather Initiative (ISWI) was to deploy arrays of small, inexpensive instruments, including magnetometers, radio telescopes, global positioning satellite receivers and all-sky cameras, around the world to allow global measurements of ionospheric and heliospheric phenomena. The ISWI programme was envisioned as a partnership between instrument providers and instrument hosts in respective countries. The United Nations Office for Outer Space Affairs (UNOOSA) played a crucial role in regards to the initiative being responsible for its implementation before it was concluded in 2012.
\end{abstract}

\section{(c) 2018 BBSCS RN SWS. All rights reserved}

Keywords: Space weather, IHY, ISWI, United Nations, COPUOS, UNISPACE+50

\section{Introduction}

In early September 2017, the Sun exhibited its immense power-producing solar flares, coronal mass ejections and highspeed solar wind as an integral part of solar activity. The events are unmatched in the past decade and have once again proven the enormous influence of the Sun over the surrounding environment (Salazar, 2017). Even at a distance of almost 150 million kilometres, these phenomena carry a great amount of energy and charged particles through space and, if they are directed towards our planet, they may cause diverse negative effects in the Earth's magnetosphere, atmosphere, ionosphere, and on the ground.

Having the potential to disrupt both land- and space- based infrastructure and threaten every continent of the world, space weather is indeed an international concern. It may affect us in many ways, e.g. disruption of communication, navigation, and satellite orbits. It also constitutes radiation hazards for astronauts and spacecraft, and may cause the collapse of electrical power grids. Exposure of our systems to adverse impacts of space weather may have catastrophic consequences and result in immense losses, both economic and societal. International coordination is necessary to effectively mitigate such impacts and to improve our capability to predict them in the future. Continuous participation of countries around the globe in both space- and ground-based measurements and forecast services is crucial in attempting to understand these phenomena better.

\section{Background}

The substantive efforts to bring together experts in many scientific fields for an international project of coordinated observations of various geophysical phenomena led to the International Geophysical Year of 1957-1958, bringing together over 70 countries. In 2004, COPUOS agreed to highlight the importance of comprehending the impacts of space weather as part of a planned commemoration of the $50^{\text {th }}$ anniversary of the International Geophysical Year 1957 (IGY), which had coincided with the beginning of the "Space age" and the launch of Sputnik-1. Consequently, the year 2007 was labelled the International Heliophysical Year. It aimed to bring worldwide attention to the importance and relevance of global cooperation in research activities in the field. The United Nations sponsored the programme and five separate events were held during the period of 2005-2009 as a dedication to IHY, before it was concluded in February 2009.

IHY marked enormous progress in the area of international space weather research and collaboration (United Nations, A/AC.105/1146). COPUOS noted the importance of building upon the success of IHY at its $52^{\text {nd }}$ session in 2009. As a followup to IHY, COPUOS noted that its Scientific and Technical Subcommittee had reached an agreement to consider a new agenda item under a three-year work plan from 2010 to 2012 (Haubold et. al., 2010). ISWI was established in 2009 with an exclusive focus on space weather to advance global science cooperation in the field by advancing and combining knowledge of solar-terrestrial physics. It not only encouraged scientists and institutions to share their discoveries, but also actively coordinated training, education and outreach activities (United Nations, A/AC.105/1138). The United Nations Office for Outer Space Affairs was responsible for implementation of ISWI under the framework of its Basic Space Science Initiative (BSSI), a longterm effort for the development of astronomy and space science through cooperative efforts at both regional and international levels, with a series of workshops held on an annual basis (Haubold and Balogh, 2014).

COPUOS concluded ISWI as an agenda item of the Scientific and Technical Subcommittee in 2012, after three successful workshops held in Nigeria, Egypt and Japan in 2010, 2011, and 2012 respectively. The workshops provided a framework for collaboration between teams of scientists, serving as an example of remarkable international cooperation in instrument operation, data collection, analysis and publication of scientific results. Eighteen instrument arrays were deployed around the globe as part of ISWI's mission to install ground-based infrastructure that helps scientists to grasp space weather impacts (United Nations, A/AC.105/1160). Despite the conclusion of ISWI as an agenda item, activities related to its work have continued under a new COPUOS agenda item on Space Weather introduced in 2013 (United Nations, A/AC.105/1001; United Nations A/AC.105/1038).

Ten years after IHY, the United Nations Office for Outer Space Affairs, together with the National Aeronautics and Space Administration (NASA), on behalf of the government of the United States, held the United Nations/United States of America Workshop on the International Space Weather Initiative: the decade after the International Heliophysical Year 2007. The workshop provided a forum for discussion on topics related to space weather, in line with the work of UNOOSA and the United Nations Committee on the Peaceful Uses of Outer Space (COPUOS). The workshop, held in Boston from 31 July to 4 August 2017, marked the $10^{\text {th }}$ anniversary of IHY, and considered future international cooperation in space weather activities linked to the preparations for the $50^{\text {th }}$ anniversary of the first United Nations Conference on the Exploration and Peaceful Uses of Outer Space (UNISPACE +50). 
The workshop, together with other flagship events under UNISPACE +50 process, addressed one of seven thematic priorities agreed by COPUOS in 2016 (United Nations, A/71/20). The issues related to the topics of the workshop and to space phenomena involving the Sun's activity are addressed by thematic priority 4: International framework for space weather services.

\section{The United Nations Office for Outer Space Affairs}

The Office for Outer Space Affairs is the United Nations office responsible for promoting international cooperation in the peaceful uses of outer space. UNOOSA serves as the secretariat for the General Assembly's only committee dealing exclusively with international cooperation in the peaceful uses of outer space: COPUOS. Moreover, it serves as the executive secretariat to the International Committee on the Global Navigation Satellite Systems and to the Space Mission Planning Advisory Group (SMPAG). UNOOSA is also responsible for implementing the Secretary-General's responsibilities under international space law and maintaining the United Nations Register of Objects Launched into Outer Space. In addition, since its approval in 2006, the United Nations Platform for Space-based Information for Disaster Management and Emergency Response (UN-SPIDER) has been developing solutions to address the limited access of developing countries to specialized technologies that can be essential in managing disasters, including threats posed by space weather events.

COPUOS serves as a forum to advance international cooperation efforts in the peaceful uses of outer space, and to promote research and exchange of information on matters concerning outer space. Its main role is to govern the exploration and use of space for the benefit of all humanity: for peace, security and development. COPUOS has played a fundamental role in the evolution of international law concerning the space domain, and it meets every year to discuss the evolution of the space agenda and advancements in space technology and applications. It reports to the Fourth Committee of the General Assembly on a yearly basis, which then adopts an annual resolution on international cooperation in the peaceful uses of outer space. Two subsidiary bodies of COPUOS were established in 1961 - the Scientific and Technical Subcommittee, and the Legal Subcommittee.

UNOOSA has a long history in assisting Member States in the use of space science, technology and their applications in support of sustainable development, and in promoting international cooperation in outer space activities. Since its establishment in 1971, UNOOSA's Programme on Space Applications has made substantial progress in developing knowledge and experience of space applications around the world through dedicated workshops, trainings and fellowships. In this regard, space weather constitutes no exception since UNOOSA, as a capacity-building body, addresses a broad range of issues. Additionally, UNOOSA, together with the ISWI Steering Committee, conducts schools, conferences, and other outreach activities to create forums for discussion, education, and exchange of information, ideas and knowledge acquired by many scientists and researchers from around the world.

\section{International Committee on Global Navigation Satellite Systems}

The International Committee on Global Navigation Satellite Systems (ICG), established in 2005 under the umbrella of the United Nations, is an informal, voluntary forum for discussions on a global level on the topics regarding GNSS for all relevant stakeholders, including governments and interested nongovernment entities. ICG serves to foster cooperation and promote new partnerships among these entities on matters of mutual interest related to civil-based positioning, navigation, timing and value-added services, together with compatibility and interoperability of GNSS. The purpose is to promote the greater use of GNSS capabilities, while increasing their use to support sustainable development, particularly in developing countries.

\section{UNISPACE +50}

The international space community realizes the importance of cooperation and improved coordination, including in the field of space weather. In 2015, COPUOS mandated UNOOSA to organize a milestone event to take place in June 2018 as a special segment of its $61 \mathrm{st}$ session celebrating the $50^{\text {th }}$ anniversary of UNISPACE I, held in Vienna in 1968.

The whole process of UNISPACE +50 not only coincides with the ever growing importance of space applications and technologies for humankind, but also with global efforts, goals and targets of three international frameworks: the 2030 Agenda for Sustainable Development and its 17 Sustainable Development Goals, the Sendai Framework for Disaster Risk Reduction 20152030 and the Paris Agreement on Climate Change. The shared goal of UNISPACE+50 is to build, together with all stakeholders, a comprehensive Space2030 agenda for the contribution of space activities to the achievement of the Sustainable Development Goals while addressing overarching, long-term development concerns, and which is based on the peaceful exploration and uses of outer space. The UNISPACE+50 event will take into account the interdependencies in the space sector and foster international cooperation, paying special attention to future space-faring and developing countries while carefully considering the long-term sustainability of outer space activities.

\section{Space Weather}

Thematic priority 4 and its five objectives provide a view that space weather is an important element in efforts to guarantee that outer space activities are conducted in a peaceful manner. The report on thematic priority 4 (United Nations, A/AC.105/1171) puts an emphasis on the importance of a collaborative approach at the international level. In particular, it aims to:

$>$ strengthen the reliability of space systems and their ability to respond to the impact of adverse space weather,

$>$ develop a road map for international coordination and information exchange of events relating to space weather and their mitigation, by means of utilize risk analysis and assessment of user needs,

$>$ increase awareness about the impacts and related risks through communication, capacity-building and outreach,

$>$ promote space weather as a global challenge, and

$>$ identify governance and cooperation mechanisms.

States must understand why it is necessary to act regarding this issue, and recognition of space weather as a global challenge will help substantively. Research and recent events, e.g. the geomagnetic storm in 1989 in Quebec or powerful solar flares of 2017, push forward the understanding of the potential severity of impacts that these phenomena may have on the world's economy and critical infrastructure. It could influence our lives in many ways, ranging from induced currents to malfunction and ageing of space and ground assets, from disruption of satellite and other communications to threatening spacecraft and astronauts with solar radiation. Damage to property and infrastructure, as well as loss of lives on Earth and in space, has to be taken into account. Space-based assets represent very crucial infrastructure for the functioning of modern human society and our reliance on them has been increasing for decades. They provide us with pivotal technology and applications, serving as a means of communication, navigation, timing, situational-awareness, Earth observation, weather prediction or climate change monitoring, to name a few. In a study published in 2017 (Riley and Love) it is estimated that for the next decade the probability of a massive solar event potentially causing damages up to trillions of dollars could be as large as $3-10$ percent, indicating that solar events are not to be underestimated nor overlooked.

To effectively address these issues and mitigate potential impacts, states must know what to do in such a situation. In the 
first place, a detailed assessment of the pathways of likely effects and assessments of vulnerability, risk and socioeconomic impacts are required for effective mitigation. Calculating probabilities and identifying new resilient designs to withstand a once-in-a-century storm is extremely vital. States themselves must identify the needs and vulnerabilities of their specific users to recognize the possibilities of protection. However, despite long-standing efforts, it is still extremely difficult to predict when the next event may happen with a satisfactory degree of precision. To comprehend what drives solar activity as well as to improve accuracy of forecasts, there is an urgent need to advance scientific understanding, bearing in mind the complexity of physical processes in the Sun-Earth system. Coordination and cooperation among scientists is crucial to achieve capability of high-precision forecasting.

Some states have already adopted appropriate national responses reflecting acknowledgement of the risks, political will to act, and engagement of critical national infrastructure. Resulting national action plans and protocols are a significant step forward in States becoming more resilient to adverse effects. Even though the United States and the United Kingdom have adopted such measures, more states have to join, and, where applicable, in a much more coordinated way. Europe has already begun involving multiple stakeholders in the field of space weather to implement policies on the regional level. An overview similar to that of Europe could be commenced within the framework of COPUOS through the agenda item on Space Weather, which falls under the Scientific and Technical Subcommittee. Additional communication and exchange of information as well as best practices in the assessment of worst-case scenarios and characterization of the level of intensity of solar storms can serve as a promotion of such efforts at the global level.

Effective coordination has to move beyond only States and United Nations entities to include other international organizations e.g. the International Space Environment Service (ISES) and the Committee on Space Research (COSPAR). Stronger international coordination in the science of forecasting, knowledge management and capabilities of warning systems could be achieved by developing a concept for space weather information protocols that would encompass early warning systems for detection and awareness-raising of potential or existing catastrophic space events. This could be done through existing space weather service providers or international bodies involved in the field, for example WMO or ISES.

UNISPACE +50 thematic priority 4 envisages a road map for international coordination and information exchange on space weather events and their mitigation as one of its objectives. This could be elaborated based on the existing road map of COSPAR and International Living With a Star (ILWS), with periodic assessments and consequential updates (Schrijver, 2015). The results of the periodic assessments could be presented to COPUOS for dissemination to States for them to consider appropriate steps to be taken in implementing new recommendations.

COPUOS has been very active in the field of space weather, but has also directed its mandate to ensure that states and international organizations conduct space activities in a sustainable way. Throughout the years, it has considered different aspects of space activities and, in 2010, an agenda item on the long-term sustainability of outer space was introduced under the Scientific and Technical Subcommittee to build upon previous efforts. A Working Group on the Long-term Sustainability of Outer Space Activities was established and has addressed thematic areas including sustainable space utilization supporting sustainable development on Earth; space debris; space operations and tools to support collaborative space situational awareness; space weather; and regulatory regimes and guidance for actors in the space arena.

In 2016 the Committee agreed to the first set of guidelines proposed by the Working Group, with a second set and preambular text under development, to be introduced to the General Assembly in 2018 (United Nations, A/AC.105/C.1/L.362/Rev.1). Guidelines 16 and 17 were recognized by participants of the United Nations/United States of America Workshop as especially relevant to future action on space weather. Under the proposed road map, these two guidelines, together with guideline 25 , play a pivotal role that is highlighted and elaborated in the report of UNISPACE +50 thematic priority 4 (United Nations, A/AC.105/1171). In order to succeed with the road map, there is a need to encourage states to progress in the implementation of the approved guidelines and to improve the capacity of states to know when to act. Establishing the process to promote and assess progress in the implementation of the COPUOS guidelines is highly desirable as it serves as a benefit for both active and emerging states. A special international coordination group on space weather could serve as a body to promote, monitor and help in implementing the guidelines. ICG could serve as a model for such an international group.

\section{“United Nations/United States of America Workshop on the International Space Weather Initiative: the decade after the International Heliophysical Year 2007"}

During preparations for the completion of the reports on each UNISPACE +50 thematic priority, several flagship events were held to coincide with the whole UNISPACE +50 process. The aim of the events was to gather relevant views and recommendations provided by the participants. The flagship event "United Nations/United States of America Workshop on the International Space Weather Initiative: the decade after the International Heliophysical Year 2007" under thematic priority 4 was organized in 2017 by UNOOSA in cooperation with NASA. Discussions during the event covered the establishment of common warning and observation systems; strategies for improvement of collection, exchange and delivery of space weather data; modelling and forecasting methods; and the improvement of accuracy, reliability and interoperability (United Nations, A/AC.105/1160). A road map was considered as a path to support capacity-building, training and awareness-raising activities. The possibility of designing a user platform that would help in identifying user requirements and promotion of synergies between communities addressing space weather impacts was also debated.

The participants of the workshop underlined that space weather is a global challenge and noted the role UNOOSA has played in fostering greater synergy and in promoting the convergence of common interest among States of COPUOS and other related national and international organizations involved in space weather efforts. With the ever growing reliance and dependence on space and ground infrastructure that may be seriously damaged by space weather, there is an urgent and growing need to understand more about the risks, origins and dynamics of such events. More advanced space weather models and forecast tools are required and must be shared and disseminated in a coordinated manner around the globe.

The participants of the workshop stressed the role of the COPUOS "Guidelines for the long-term sustainability of outer space activities", as they provide an initial basis for coordination and actions for Member States and relevant organizations at the international level. There are many instruments to be included in coordination efforts. Among the most important is providing decision- and policy-makers with relevant information by raising awareness of hazards and risks related to space weather. When risks are identified, the steps to mitigate them could be taken more effectively. Improving resiliency to address them is a process in which coordination and communication of best possible designs and engineering could lead to improved mitigation or complete avoidance of adverse effects. When infrastructure is better protected, data can be gathered more reliably and, through increased coordination, open-data sharing and real-time data 
accessibility, stakeholders can avoid duplication of efforts and help each other in forecasting hazardous events. Identifying the most important data to be shared is the key as it improves predictions and preparedness for space weather phenomena.

Socioeconomic impacts, however, are different for every nation and their end-users as they have different vulnerabilities and needs. Impact studies and subsequent sharing of best practices for assessment and mitigation would greatly advance resiliency and protection of key infrastructure. Emerging nations wishing to engage in space weather science have to be supported through capacity-building and technical guidance, and such opportunities should be increasingly developed within the United Nations. In this regard, the role of the private sector cannot be overlooked as it serves as an additional component and stakeholder in many ways, including by providing funds and knowledge in support of research and protection of critical infrastructure on the ground as well as in space. Outreach has to be global and cover a wide range of target groups, from the general public to engineers and designers, from students to decision-makers.

The successful role of ISWI was highlighted during the workshop. ISWI offered significant opportunities for space science and technology education, and the level of activities relating to space weather has expanded ever since it commenced in 2009. Regarding the UNISPACE +50 process, the participants of the workshop noted its importance as a unique opportunity to offer new insights for COPUOS to consider in its future work and for improved space weather services. There is a need to monitor progress in the field of space weather, a task that could be delivered by already established relevant stakeholders, including UNOOSA, COSPAR, ICAO, WMO, ISES, the International Astronomical Union (IAU), or the Scientific Committee on Solar Terrestrial Physics (SCOSTEP), to name a few.

Several recommendations were agreed upon as the outcome of the workshop. The need to promote increased international cooperation in order to meet the present and future requirements was highlighted, with a call for a coordination mechanism with voluntary participation. UNOOSA would support such a mechanism under the framework of COPUOS. To enable effective coordination, all the constraints and limitations to open communication and data flows should be eliminated, with open data policy promoted at the national level. Complementary to coordination within ISWI, partnerships with other relevant scientific organizations at the international level are to be either established or nourished to ensure that capacity-building activities are carried out effectively and benefit all Member States. All the knowledge acquired during activities falling under ISWI should be disseminated and made available for the scientific community and public through relevant pipelines including ISWI newsletters, website and other media. Finally, enhanced cooperation to identify the needs of Member States should be promoted in the UNISPACE +50 process.

The workshop also focused its attention on discussing links to the 2030 Agenda for Sustainable Development and its 17 Sustainable Development Goals (United Nations, A/RES/70/1). Three of the goals were addressed in the discussions - Goal 4: Quality education, Goal 9: Industry, innovation and infrastructure; and Goal 17: Partnerships for the Goals.

\section{Conclusion}

This paper reviews the evolution of space weather activities under the auspices of UNOOSA in the past years, with the aim of providing an overview of the relevant steps taken, planned and recommended for the future. International collaboration has been growing for years, especially after increasing recognition of space weather as a global challenge that requires cooperation to address. Space science data acquired through many activities provides us with crucial knowledge of the potential hazards resulting from space weather events. However, all end-users and states are expected to experience different impacts, as their vulnerabilities and preparedness are different. This has to be elaborated in much deeper detail so that mitigation efforts are effective and negative impacts are as limited as possible, potentially eliminated.

Advancing the development of improved operational space weather services and improving resilience against adverse space weather effects and impacts must carry on with the deployment of new arrays and improvements in design of ground and space infrastructure, as well as by awareness-raising through outreach, education and capacity-building in order to bring more states and people into space science. The initiatives, including IHY, IGY and ISWI, have indicated great potential for cooperation among nations in addressing space weather. Ten years after IHY, the workshop on ISWI was held in Boston, the United States, in 2017 to debate future courses of action.

The recommendation to establish a new international coordination group on space weather discussed during the Workshop and referred to in the report of the thematic priority 4 was also debated during $55^{\text {th }}$ session of the Scientific and Technical Subcommittee of COPUOS. A progress report was submitted by the Expert Group on Space Weather recommending that the terms of reference for the international coordination group be proposed by 2019 and further developed during an international space weather workshop in the third quarter of 2019, with the aim of presenting them to the Subcommittee in 2020 for final approval (United Nations, A/AC.105/C.1/L.365/Add.1).

With the growing importance of technologies and applications that are vulnerable to events related to space weather, billions of dollars are at stake during any major solar flare or coronal mass ejection. Moreover, space technology supports humanity's common goals of addressing global challenges. Space weather research and global collaboration would therefore promote sustainable development through the prevention of catastrophic disruptions of critical infrastructure and services. Despite the fact that a lot has been achieved, there is more to be done in the future, with international cooperation at the core of any efforts.

\section{Acknowledgments}

The authors acknowledge advice and support from representatives of States members of the United Nations and their space agencies and institutions in the exploration of the interaction between space science and space technology for the development of space policy for the benefit of nations.

The views expressed herein are those of the author(s) and do not necessarily reflect the views of the United Nations. 


\section{References}

Carolus J. Schrijver, et al.: 2015, Understanding space weather to shield society: A global road map for 2015 - 2025 commissioned by COSPAR and ILWS. Advances in Space $\begin{array}{llll}\text { Research } & 55 & \text { (2015) 2745-2807. }\end{array}$ https://www.sciencedirect.com/science/article/pii/S02732 27715002252

D.E. Salazar.: 2017, Monster Solar Flare Marks 7th Powerful Sun Storm in 7 Days, space.com. https: / /www.space.com/38115-sun-monster-solar-flaresseven-days.html

Draft Report of the Scientific and Technical Subcommittee on its fifty-fifth session, held in Vienna from 29 January to 9 February 2018, UN General Assembly Document, A/AC.105/C.1/L.365/Add.1, pp. 2-3.

Guidelines for the long-term sustainability of outer space activities, UN General Assembly Document, A/AC.105/C.1/L.362/Rev.1, 10 October 2017, pp. 6-9.

H. J. Haubold and W. Balogh.: 2014, The United Nations Basic Space Science Initiative, United Nations Office for Outer Space Affairs. http://adsabs.harvard.edu/abs/2014EGUGA..1616183H

H. J. Haubold, S. Gadimova and W. Balogh.: 2010, Contributions of the United Nations Office for Outer Space Affairs to the International Space Weather Initiative (ISWI), United Nations.

P. Riley and J. Love.: 2017 Extreme geomagnetic storms: Probabilistic forecasts and their uncertainties, Space Weather Quarterly Volume 14, Issue 1, 2017.

Report of the Committee on the Peaceful Uses of Outer Space on its fifty-ninth session, held in Vienna from 8 June to 17 June 2016, UN General Assembly Document, A/71/20, pp. 47-52.

Report of the Scientific and Technical Subcommittee on its fortyninth session, held in Vienna from 6 February to 17 February 2012, UN General Assembly Document, A/AC.105/1001, pp. 27-28.

Report of the Scientific and Technical Subcommittee on its fiftieth session, held in Vienna from 11 February to 22 February 2013, UN General Assembly Document, A/AC.105/1038, pp. 25-27.

Report of the Scientific and Technical Subcommittee on its fiftyfourth session, held in Vienna from 30 January to 10 February 2017, UN General Assembly Document, A/AC.105/1138, pp. 29

Report of the United Nations/United States of America Workshop on the International Space Weather Initiative: the decade after the International Heliophysical Year 2007, UN General Assembly Document, A/AC.105/1160, 11 September 2017.

Space Weather: Special Report of the Inter-Agency Meeting on Outer Space Activities on Developments within the United Nations System related to Space Weather, United Nations General Assembly Document, A/AC.105/1146, 28 April 2017, pp. 5, 14.

Thematic priority 4: International framework for space weather services, UN General Assembly Document, A/AC.105/1171, 20 November 2017

United Nations, Transforming our world: the 2030 Agenda for Sustainable Development, UN General Assembly Resolution, A/RES/70/1, 21 October 2015. 